\title{
Two Sufficient Conditions for Convex Ordering on Risk Aggregation
}

\author{
Dan Zhu $(\mathbb{D})$ and Chuancun Yin (iD) \\ School of Statistics, Qufu Normal University, Shandong 273165, China \\ Correspondence should be addressed to Chuancun Yin; ccyin@mail.qfnu.edu.cn
}

Received 22 October 2017; Accepted 28 December 2017; Published 1 February 2018

Academic Editor: Lucas Jodar

Copyright (C) 2018 Dan Zhu and Chuancun Yin. This is an open access article distributed under the Creative Commons Attribution License, which permits unrestricted use, distribution, and reproduction in any medium, provided the original work is properly cited.

We define new stochastic orders in higher dimensions called weak correlation orders. It is shown that weak correlation orders imply stop-loss order of sums of multivariate dependent risks with the same marginals. Moreover, some properties and relations of stochastic orders are discussed.

\section{Introduction}

Correlation order as an important stochastic order relation was first introduced by Joe [1]; Dhaene and Goovaerts [2] studied the bivariate case with the same marginals. After that, the bivariate case has been generalized by $\mathrm{Lu}$ and Zhang [3]. Recall that given two random vectors $\left(X_{1}, \ldots, X_{n}\right)$ and $\left(Y_{1}, \ldots, Y_{n}\right)$ with the same marginals, $\left(X_{1}, \ldots, X_{n}\right)$ is said to be less correlated than $\left(Y_{1}, \ldots, Y_{n}\right)$, written as $\left(X_{1}, \ldots, X_{n}\right) \leq_{c}\left(Y_{1}, \ldots, Y_{n}\right)$, if for every pair of disjoint subsets $A_{1}$ and $A_{2}$ of $\{1,2, \ldots, n\}$,

$$
\begin{aligned}
& \operatorname{cov}\left(f\left(X_{i}, i \in A_{1}\right), g\left(X_{j}, j \in A_{2}\right)\right) \\
& \quad \leq \operatorname{cov}\left(f\left(Y_{i}, i \in A_{1}\right), g\left(Y_{j}, j \in A_{2}\right)\right),
\end{aligned}
$$

where $f$ and $g$ are nondecreasing functions for which the covariances exist. The main result of $\mathrm{Lu}$ and Zhang [3] showed that the correlation order implied stop-loss order for portfolios of multivariate dependent risks; that is, $\left(X_{1}, \ldots, X_{n}\right) \leq_{c}\left(Y_{1}, \ldots, Y_{n}\right)$ implies $\sum_{i=1}^{n} X_{i} \leq_{\text {sl }} \sum_{i=1}^{n} Y_{i}$. Stoploss order as a special case of convex order is the most frequently used order relation for the comparison of risks, written as $X \leq_{\mathrm{sl}} Y$, for any two random variables $X$ and $Y$, if and only if the inequality $E\left[(X-d)_{+}\right] \leq E\left[(Y-d)_{+}\right]$holds for all real $d$, where $(\xi)_{+}$denotes the positive part of the real $\xi$. In addition, $X$ is said to precede $Y$ in the convex order sense; define $X \leq_{\mathrm{cx}} Y$, if and only if $X \leq_{\mathrm{sl}} Y$ and $E[X]=E[Y]$.
More details and other characterizations about stop-loss order can be found in Denuit et al. [4], Dhaene et al. [5], Landsman and Tsanakas [6], and Shaked and Shanthikumar [7]. Rüschendorf [8] introduced a new dependence order among risks called the weakly conditional increasing in sequence order; by definition given two random vectors $X=$ $\left(X_{1}, \ldots, X_{n}\right)$ and $Y=\left(Y_{1}, \ldots, Y_{n}\right)$ with the same marginals, $\left(X_{1}, \ldots, X_{n}\right)$ is said to be smaller than $\left(Y_{1}, \ldots, Y_{n}\right)$ in the weakly conditional increasing in sequence order, written as $X \leq_{\text {wcs }} Y$, if for all $t \in \mathbb{R}$, all $1 \leq i \leq n-1$ and $\tilde{f}$ is monotonically nondecreasing,

$$
\begin{aligned}
& \operatorname{cov}\left(I\left(X_{i}>t\right), \tilde{f}\left(X_{(i+1)}\right)\right) \\
& \quad \leq \operatorname{cov}\left(I\left(Y_{i}>t\right), \tilde{f}\left(Y_{(i+1)}\right)\right),
\end{aligned}
$$

where $X_{(i+1)}=\left(X_{i+1}, \ldots, X_{n}\right)$ and $Y_{(i+1)}=\left(Y_{i+1}, \ldots, Y_{n}\right)$. It is showed that more positive dependence with respect to the wcs ordering implied more risk with respect to the supermodular ordering (see Rüschendorf [8] for the definitions of supermodular function and supermodular ordering) for $n$-dimensional random vectors; that is, $X \leq_{\text {wcs }} Y$ implies $X \leq_{\mathrm{sm}} Y$. Note that, in (1), we let $f\left(X_{i}, i \in A_{1}\right)=I\left\{X_{i}>\right.$ t\} and $g\left(X_{j}, j \in A_{2}\right)=\tilde{f}\left(X_{(i+1)}\right),(2)$ is an immediate consequence of (1), and by Example 5 of this paper, the weakly conditional increasing in sequence order is weaker than correlation order, while the stop-loss order still holds by Müller [9]. Enlightened by this, we are committed to find 
more general conditions for the multivariate case which can also imply stop-loss order.

In this short note, we give the concepts of weak correlation orders in higher dimensions and show that the weak correlation orders imply stop-loss order of multivariate dependent risks with the same marginals. The remainder of the paper is organized as follows. In Section 2, we introduce some concepts of stochastic orders including the new definitions and discuss the properties and stochastic order relations. The main results of this paper are presented and proved in Section 3.

\section{Preliminaries}

Given Fréchet space $\mathfrak{R}\left(F_{1}, \ldots, F_{n}\right)$ of all $n$-dimensional random vectors $X=\left(X_{1}, \ldots, X_{n}\right)$, we have $F_{1}, \ldots, F_{n}$ as marginal distributions, where $F_{i}(x):=P\left(X_{i} \leq x\right)$, and the joint distribution function is $F_{X}\left(x_{1}, \ldots, x_{n}\right):=P\left(X_{1} \leq\right.$ $\left.x_{1}, \ldots, X_{n} \leq x_{n}\right)$. For all $X \in \mathfrak{R}\left(F_{1}, \ldots, F_{n}\right)$, we have the following inequality:

$$
\begin{aligned}
M_{n}\left(x_{1}, \ldots, x_{n}\right) \leq F_{X}\left(x_{1}, \ldots, x_{n}\right) \leq & W_{n}\left(x_{1}, \ldots, x_{n}\right) \\
& \forall\left(x_{1}, \ldots, x_{n}\right) \in \mathbb{R}^{n},
\end{aligned}
$$

where $W_{n}\left(x_{1}, \ldots, x_{n}\right):=\min \left\{F_{1}\left(x_{1}\right), \ldots, F_{n}\left(x_{n}\right)\right\}$ and

$$
M_{n}\left(x_{1}, \ldots, x_{n}\right):=\max \left\{\sum_{i=1}^{n} F_{i}\left(x_{i}\right)-n+1,0\right\}
$$

are called Fréchet upper bound and Fréchet lower bound of $\mathfrak{R}\left(F_{1}, \ldots, F_{n}\right)$, respectively. Remark that $W_{n}$ is reachable in $\mathfrak{R}\left(F_{1}, \ldots, F_{n}\right)$ and when $n=2, M_{2}$ is indeed a distribution function. However, when $n \geq 3, M_{n}$ is no longer always a distribution function (see Denuit et al. [4]). A necessary and sufficient condition for $M_{n}$ to be a distribution function in $\mathfrak{R}\left(F_{1}, \ldots, F_{n}\right)$ can be found in Dhaene and Denuit [10]. Throughout the short note, it is assumed that all random variables are real random variables on this space.

Comparing random variables is the essence of the actuarial profession; in order to acquire more general results, we give the notion of weak correlation orders as follows.

Definition 1. Let random vectors $X=\left(X_{1}, \ldots, X_{n}\right)$ and $Y=$ $\left(Y_{1}, \ldots, Y_{n}\right)$ be elements of $\mathfrak{R}\left(F_{1}, \ldots, F_{n}\right)$, and we say that $X$ is smaller than $Y$ in type I weak correlation order, written as $X \leq_{\text {wco-I }} Y$, if for all $t, s \in \mathbb{R}, 1 \leq k \leq n-1$, any of the following equivalent conditions holds:

$$
\text { (i) } \begin{aligned}
& \operatorname{cov}\left(I\left\{\sum_{i=1}^{k} X_{i}>t\right\}, I\left\{X_{k+1}>s\right\}\right) \\
\leq & \operatorname{cov}\left(I\left\{\sum_{i=1}^{k} Y_{i}>t\right\}, I\left\{Y_{k+1}>s\right\}\right),
\end{aligned}
$$

$$
\begin{aligned}
& \text { (ii) } \operatorname{cov}\left(I\left\{\sum_{i=1}^{k} X_{i} \leq t\right\}, I\left\{X_{k+1} \leq s\right\}\right) \\
& \leq \operatorname{cov}\left(I\left\{\sum_{i=1}^{k} Y_{i} \leq t\right\}, I\left\{Y_{k+1} \leq s\right\}\right) \text {, }
\end{aligned}
$$

where $I$ is an indicator function.

Remark 2. The equivalence between (5) can be obtained as follows. We have

$$
\begin{aligned}
& \operatorname{cov}\left(I\left\{\sum_{i=1}^{k} X_{i}>t\right\}, I\left\{X_{k+1}>s\right\}\right)=P\left(\sum_{i=1}^{k} X_{i}\right. \\
& \left.>t, X_{k+1}>s\right)-P\left(\sum_{i=1}^{k} X_{i}>t\right) P\left(X_{k+1}>s\right)=1 \\
& -P\left(\sum_{i=1}^{k} X_{i} \leq t\right)-P\left(X_{k+1} \leq s\right)+P\left(\sum_{i=1}^{k} X_{i}\right. \\
& \left.\leq t, X_{k+1} \leq s\right)-\left[1-P\left(\sum_{i=1}^{k} X_{i} \leq t\right)\right. \\
& \left.-P\left(X_{k+1} \leq s\right)+P\left(\sum_{i=1}^{k} X_{i} \leq t\right) P\left(X_{k+1} \leq s\right)\right] \\
& =P\left(\sum_{i=1}^{k} X_{i} \leq t, X_{k+1} \leq s\right)-P\left(\sum_{i=1}^{k} X_{i} \leq t\right) \\
& \cdot P\left(X_{k+1} \leq s\right) \\
& =\operatorname{cov}\left(I\left\{\sum_{i=1}^{k} X_{i} \leq t\right\}, I\left\{X_{k+1} \leq s\right\}\right),
\end{aligned}
$$

and by the same way, we obtain

$$
\begin{aligned}
& \operatorname{cov}\left(I\left\{\sum_{i=1}^{k} Y_{i}>t\right\}, I\left\{Y_{k+1}>s\right\}\right) \\
& =\operatorname{cov}\left(I\left\{\sum_{i=1}^{k} Y_{i} \leq t\right\}, I\left\{Y_{k+1} \leq s\right\}\right) .
\end{aligned}
$$

Hence, (5) are equivalent. Moreover, (8) and (9) are also equivalent.

Definition 3. Random vectors $X=\left(X_{1}, \ldots, X_{n}\right)$ and $Y=$ $\left(Y_{1}, \ldots, Y_{n}\right)$ are elements of $\mathfrak{R}\left(F_{1}, \ldots, F_{n}\right)$, and we say that $X$ is smaller than $Y$ in type II weak correlation order, written as $X \leq_{\text {wco-II }} Y$, if for all $t, s \in \mathbb{R}, 1 \leq k \leq n-1$, any of the following equivalent conditions holds:

$$
\begin{aligned}
& \text { (i) } \operatorname{cov}\left(I\left\{X_{k}>t\right\}, I\left\{\sum_{i=k+1}^{n} X_{i}>s\right\}\right) \\
& \leq \operatorname{cov}\left(I\left\{Y_{k}>t\right\}, I\left\{\sum_{i=k+1}^{n} Y_{i}>s\right\}\right),
\end{aligned}
$$




$$
\begin{aligned}
& \text { (ii) } \operatorname{cov}\left(I\left\{X_{k} \leq t\right\}, I\left\{\sum_{i=k+1}^{n} X_{i} \leq s\right\}\right) \\
& \leq \operatorname{cov}\left(I\left\{Y_{k} \leq t\right\}, I\left\{\sum_{i=k+1}^{n} Y_{i} \leq s\right\}\right) \text {. }
\end{aligned}
$$

Remark 4. Obviously, (8) can be derived from (2) by letting

$$
\tilde{f}\left(X_{(i+1)}\right)=I\left\{\sum_{j=i+1}^{n} X_{j}>s\right\} .
$$

Let random vectors $X=\left(X_{1}, \ldots, X_{n}\right)$ and $Y=$ $\left(Y_{1}, \ldots, Y_{n}\right)$ be elements of $\mathfrak{R}\left(F_{1}, \ldots, F_{n}\right)$ with values in $\mathbb{R}^{n}, F_{X}$ is the distribution function, and $\bar{F}_{X}$ is the survival function of $X$; define $X \leq_{\mathrm{uo}} Y$, iff $\bar{F}_{X}(x) \leq \bar{F}_{Y}(x)$, for any $x \in \mathbb{R}^{n} ; X \leq_{\mathrm{lo}} Y$, iff $F_{X}(x) \geq F_{Y}(x)$, for any $x \in \mathbb{R}^{n}$; $X \leq_{\text {sm }} Y$, iff $E f(X) \leq E f(Y)$, for all supermodular functions $f$ such that the expectations exist. For more discussion about supermodular order (sm order) and orthant orders (uo order and lo order), see Shaked and Shanthikumar [11], Denuit and Mesfioui [12], and Kzldemir and Privault [13]. The following relations are well known by the definitions above, Lu and Zhang [3] and Müller [9]:

(i) $X \leq_{c} Y \Rightarrow X \leq_{\mathrm{wcs}} Y \Rightarrow X \leq_{\mathrm{sm}} Y \Rightarrow X \leq_{\mathrm{uo}} Y$ and $X \geq_{\text {lo }} Y$;

(ii) $X \leq_{c} Y \Rightarrow X \leq_{\text {wcs }} Y \Rightarrow X \leq_{\text {wco-II }} Y$;

(iii) $X \leq_{c} Y \Rightarrow X \leq_{\text {wco-I }} Y$.

Specially, these stochastic orders are equivalent in the bivariate case.

It is well known that correlated order and weakly conditional increasing in sequence order can deduce the weak correlation orders, but the converse is not true in case $n \geq 3$; the following example illustrates this point.

Example 5. Let $X_{i}$ and $Y_{i}$ be random valuables with distributions as $P\left(X_{i}=0\right)=2 / 3, P\left(X_{i}=1\right)=1 / 3, P\left(Y_{i}=\right.$ $0)=2 / 3$, and $P\left(Y_{i}=1\right)=1 / 3, i=1,2,3$. In addition, $X=\left(X_{1}, X_{2}, X_{3}\right)$ and $Y=\left(Y_{1}, Y_{2}, Y_{3}\right)$ are random vectors with the following joint distributions:

$$
\begin{aligned}
& P\left(X_{1}=0, X_{2}=0, X_{3}=0\right)=\frac{2}{9} \\
& P\left(X_{1}=1, X_{2}=0, X_{3}=0\right)=\frac{2}{9} \\
& P\left(X_{1}=0, X_{2}=1, X_{3}=0\right)=\frac{2}{9} \\
& P\left(X_{1}=0, X_{2}=0, X_{3}=1\right)=\frac{1}{9} \\
& P\left(X_{1}=1, X_{2}=0, X_{3}=1\right)=\frac{1}{9} \\
& P\left(X_{1}=0, X_{2}=1, X_{3}=1\right)=\frac{1}{9} \\
& P\left(Y_{1}=1, Y_{2}=0, Y_{3}=0\right)=\frac{1}{3}
\end{aligned}
$$

$$
\begin{aligned}
& P\left(Y_{1}=0, Y_{2}=1, Y_{3}=0\right)=\frac{1}{3}, \\
& P\left(Y_{1}=0, Y_{2}=0, Y_{3}=1\right)=\frac{1}{3} .
\end{aligned}
$$

For all $t, s \in \mathbb{R}, k=1,2$, it is easy to get that

$$
\begin{aligned}
& \operatorname{cov}\left(I\left\{\sum_{i=1}^{k} Y_{i}>t\right\}, I\left\{Y_{k+1}>s\right\}\right) \\
& \leq \operatorname{cov}\left(I\left\{\sum_{i=1}^{k} X_{i}>t\right\}, I\left\{X_{k+1}>s\right\}\right), \\
& \operatorname{cov}\left(I\left\{Y_{k}>t\right\}, I\left\{\sum_{i=k+1}^{n} Y_{i}>s\right\}\right) \\
& \leq \operatorname{cov}\left(I\left\{X_{k}>t\right\}, I\left\{\sum_{i=k+1}^{n} X_{i}>s\right\}\right) .
\end{aligned}
$$

However, for two nondecreasing functions $f\left(u_{1}\right)=u_{1}$ and $g\left(u_{2}, u_{3}\right)=I\left(u_{2} \geq 1, u_{3} \geq 1\right)$, we have

$$
\operatorname{cov}\left(f\left(Y_{1}\right), g\left(Y_{2}, Y_{3}\right)\right) \geq \operatorname{cov}\left(f\left(X_{1}\right), g\left(X_{2}, X_{3}\right)\right) \text {. }
$$

This is because

$$
\begin{aligned}
\operatorname{cov}( & \left.f\left(Y_{1}\right), g\left(Y_{2}, Y_{3}\right)\right) \\
= & E\left(f\left(Y_{1}\right) \cdot g\left(Y_{2}, Y_{3}\right)\right)-E\left(f\left(Y_{1}\right)\right) \\
& \cdot E\left(g\left(Y_{2}, Y_{3}\right)\right) \\
= & E\left(Y_{1} \cdot I\left(Y_{2} \geq 1, Y_{3} \geq 1\right)\right)-E\left(Y_{1}\right) \\
& \cdot P\left(Y_{2} \geq 1, Y_{3} \geq 1\right)=0-\frac{1}{3} P\left(Y_{2} \geq 1, Y_{3} \geq 1\right) \\
= & 0 .
\end{aligned}
$$

In the same way, we can get

$$
\operatorname{cov}\left(f\left(X_{1}\right), g\left(X_{2}, X_{3}\right)\right)=-\frac{1}{27} \text {. }
$$

Then we obtain $Y \leq_{\text {wco-I }} X \nRightarrow Y \leq_{c} X$ and $Y \leq_{\text {wco-II }} X \nRightarrow$ $Y \leq_{c} X$.

Let $f_{1}\left(u_{1}, u_{2}\right)=I\left(u_{1} \geq 1, u_{2} \geq 1\right)$, so $f_{1}$ is nondecreasing; then we have

$$
\begin{aligned}
\operatorname{cov} & \left(I\left(X_{1} \geq 1\right), f_{1}\left(X_{2}, X_{3}\right)\right) \\
= & \operatorname{cov}\left(I\left(X_{1} \geq 1\right), I\left(X_{2} \geq 1, X_{3} \geq 1\right)\right) \\
= & P\left(X_{1} \geq 1, X_{2} \geq 1, X_{3} \geq 1\right)-P\left(X_{1} \geq 1\right) \\
& \cdot P\left(X_{2} \geq 1, X_{3} \geq 1\right)=0-\frac{1}{3} \cdot \frac{1}{9}=-\frac{1}{27} .
\end{aligned}
$$

Similarly,

$$
\begin{aligned}
& \operatorname{cov}\left(I\left(Y_{1} \geq 1\right), f_{1}\left(Y_{2}, Y_{3}\right)\right) \\
& \quad=\operatorname{cov}\left(I\left(Y_{1} \geq 1\right), I\left(Y_{2} \geq 1, Y_{3} \geq 1\right)\right)=0,
\end{aligned}
$$

so $Y \leq_{\text {wco-II }} X$ cannot deduce $Y \leq_{\text {wcs }} X$. 
The next property is straightforward; we omitted all the minor details.

Property 6. Let two random vectors $X=\left(X_{1}, \ldots, X_{n}\right)$ and $Y=\left(Y_{1}, \ldots, Y_{n}\right)$ be elements of $\mathfrak{R}\left(F_{1}, \ldots, F_{n}\right)$, for any independent random vector $Z=\left(Z_{1}, \ldots, Z_{m}\right)$ which is independent of $X$ and $Y$; if $X \leq_{\text {wco-I }} Y$, we have

$$
\begin{aligned}
& \left(X_{1}, \ldots, X_{n}, Z_{1}, \ldots, Z_{m}\right) \\
& \quad \leq_{\text {wco-I }}\left(Y_{1}, \ldots, Y_{n}, Z_{1}, \ldots, Z_{m}\right),
\end{aligned}
$$

and if $X \leq_{\text {wco-II }} Y$, we can get

$$
\begin{aligned}
& \left(Z_{1}, \ldots, Z_{m}, X_{1}, \ldots, X_{n}\right) \\
& \quad \leq_{\text {wco-II }}\left(Z_{1}, \ldots, Z_{m}, Y_{1}, \ldots, Y_{n}\right) .
\end{aligned}
$$

\section{Main Results and Proofs}

In this section, we will give the main results of this paper. That the correlation order implies stop-loss order for portfolios of multivariate dependent risks has been investigated by Lu and Zhang [3] and Zhang and Weng [14]. In the next theorems, we will show that the property still holds in weak correlation orders.

Theorem 7. Let $X=\left(X_{1}, \ldots, X_{n}\right)$ and $Y=\left(Y_{1}, \ldots, Y_{n}\right)$ be elements of $\Re\left(F_{1}, \ldots, F_{n}\right)$, and if $X \leq_{\text {wco-I }} Y$, then

$$
\sum_{i=1}^{n} X_{i} \leq_{s l} \sum_{i=1}^{n} Y_{i} .
$$

To prove Theorem 7, we need the following two lemmas. For simplicity, let random variables marked with asterisks be independent, and every random variable marked with asterisk has the same distribution with its original.

Lemma 8. For any random vector $\left(X_{1}, X_{2}\right)$ and for all $d \in \mathbb{R}$, the following equality holds:

$$
\begin{aligned}
E & \left(X_{1}+X_{2}-d\right)_{+}-E\left(X_{1}^{*}+X_{2}^{*}-d\right)_{+} \\
& =\int_{-\infty}^{\infty} \operatorname{cov}\left(I\left\{X_{1}>x\right\}, I\left\{X_{2}>d-x\right\}\right) d x .
\end{aligned}
$$

Proof. For any $x_{1}, x_{2} \in \mathbb{R}$, we have

$$
\left(x_{1}+x_{2}-d\right)_{+}=\int_{-\infty}^{\infty} I\left\{x_{1}>x, x_{2}>d-x\right\} d x
$$

so that

$$
\begin{gathered}
E\left(X_{1}+X_{2}-d\right)_{+}-E\left(X_{1}^{*}+X_{2}^{*}-d\right)_{+} \\
=\int_{-\infty}^{\infty}\left[E\left(I\left\{X_{1}>x, X_{2}>d-x\right\}\right)\right. \\
\left.-E\left(I\left\{X_{1}^{*}>x, X_{2}^{*}>d-x\right\}\right)\right] d x \\
=\int_{-\infty}^{\infty}\left[P\left(X_{1}>x, X_{2}>d-x\right)\right. \\
\left.-P\left(X_{1}^{*}>x, X_{2}^{*}>d-x\right)\right] d x
\end{gathered}
$$

$$
\begin{aligned}
& =\int_{-\infty}^{\infty}\left[E\left(I\left\{X_{1}>x\right\} I\left\{X_{2}>d-x\right\}\right)\right. \\
& \left.-E\left(I\left\{X_{1}>x\right\}\right) E\left(I\left\{X_{2}>d-x\right\}\right)\right] d x \\
& =\int_{-\infty}^{\infty} \operatorname{cov}\left(I\left\{X_{1}>x\right\}, I\left\{X_{2}>d-x\right\}\right) d x .
\end{aligned}
$$

Lemma 9 (Shaked and Shanthikumar [7]). If random variables $X_{1}, Y_{1}$ satisfy that $X_{1} \leq_{s l} Y_{1}, Z_{1}$ and $Z_{2}$ have the same distribution and are independent of $X_{1}$ and $Y_{1}$, then $X_{1}+$ $Z_{1} \leq_{s l} Y_{1}+Z_{2}$.

Proof of Theorem 7. For bivariate case, by Lemma 8 we have

$$
\begin{aligned}
E & \left(X_{1}+X_{2}-d\right)_{+}-E\left(Y_{1}+Y_{2}-d\right)_{+} \\
& =\int_{-\infty}^{\infty}\left[\operatorname{cov}\left(I\left\{X_{1}>x\right\}, I\left\{X_{2}>d-x\right\}\right)\right. \\
& \left.-\operatorname{cov}\left(I\left\{Y_{1}>x\right\}, I\left\{Y_{2}>d-x\right\}\right)\right] d x \leq 0 .
\end{aligned}
$$

Assume that it is true for $n-1$ that we will prove that it is also true for $n$ in the following. Define symbols $X_{(n-1)}=X_{1}+$ $X_{2}+\cdots+X_{n-1}, Y_{(n-1)}=Y_{1}+Y_{2}+\cdots+Y_{n-1}$ and $X_{(n-1)}^{*}=$ $\left(X_{1}+X_{2}+\cdots+X_{n-1}\right)^{*}, Y_{(n-1)}^{*}=\left(Y_{1}+Y_{2}+\cdots+Y_{n-1}\right)^{*}$, and from Lemma 8 , we have

$$
\begin{aligned}
& E\left(X_{(n-1)}+X_{n}-d\right)_{+}-E\left(X_{(n-1)}^{*}+X_{n}^{*}-d\right)_{+} \\
& \quad=\int_{-\infty}^{\infty} \operatorname{cov}\left(I\left\{X_{(n-1)}>x\right\}, I\left\{X_{n}>d-x\right\}\right) d x \\
& \quad \leq \int_{-\infty}^{\infty} \operatorname{cov}\left(I\left\{Y_{(n-1)}>x\right\}, I\left\{Y_{n}>d-x\right\}\right) d x \\
& \quad=E\left(Y_{(n-1)}+Y_{n}-d\right)_{+}-E\left(Y_{(n-1)}^{*}+Y_{n}^{*}-d\right)_{+},
\end{aligned}
$$

so that

$$
\begin{aligned}
& E\left(X_{(n-1)}+X_{n}-d\right)_{+}-E\left(Y_{(n-1)}+Y_{n}-d\right)_{+} \\
& \quad \leq E\left(X_{(n-1)}^{*}+X_{n}^{*}-d\right)_{+}-E\left(Y_{(n-1)}^{*}+Y_{n}^{*}-d\right)_{+} .
\end{aligned}
$$

Since $X_{n}^{*}$ and $Y_{n}^{*}$ have the same distribution, by induction and Lemma 9, we obtain $E\left(X_{(n-1)}^{*}+X_{n}^{*}-d\right)_{+}-E\left(Y_{(n-1)}^{*}+Y_{n}^{*}-d\right)_{+} \leq$ 0 . Hence, we finish the proof.

The next theorem shows that $\sum_{i=1}^{n} X_{i} \leq_{\mathrm{sl}} \sum_{i=1}^{n} Y_{i}$ still holds in wco-II order.

Theorem 10. Let $X=\left(X_{1}, \ldots, X_{n}\right)$ and $Y=\left(Y_{1}, \ldots, Y_{n}\right)$ be elements of $\mathfrak{R}\left(F_{1}, \ldots, F_{n}\right)$; if $X \leq_{w c o-I I} Y$, then

$$
\sum_{i=1}^{n} X_{i} \leq_{s l} \sum_{i=1}^{n} Y_{i} .
$$

Proof. The proof follows immediately by the same method as Theorem 7 and Lemmas 8 and 9. 
Remark 11. In fact, since $X \leq_{\text {wco-II }} Y$, it follows from Theorem 7 that

$$
\sum_{i=1}^{n} X_{n-i+1} \leq_{\mathrm{sl}} \sum_{i=1}^{n} Y_{n-i+1} .
$$

Remark 12. If $Y=\left(Y_{1}, \ldots, Y_{n}\right)$ is a random vector in $\mathfrak{R}\left(F_{1}, \ldots, F_{n}\right)$, such that $X \leq_{\text {wco-I }} Y$ or $X \leq_{\text {wco-II }} Y$ for all $X=$ $\left(X_{1}, \ldots, X_{n}\right) \in \mathfrak{R}\left(F_{1}, \ldots, F_{n}\right)$, then $Y$ is comonotonic. Recall the definition of comonotonic: $Y$ is said to be comonotonic, if $F_{Y}(x)=\min _{1 \leq k \leq n} F_{k}\left(x_{k}\right)$ for any $x=\left(x_{1}, \ldots, x_{n}\right) \in R^{n}$. So $F_{Y}(x)=W_{n}(x)$ is reachable in $\mathfrak{R}\left(F_{1}, \ldots, F_{n}\right)$.

Remark 13. Let $l_{i}$ and $\mu_{i}$ be the essential infimum and essential supremum of a random variable $X_{i}, X=\left(X_{1}, \ldots, X_{n}\right)$ is a fixed random vector in $\Re\left(F_{1}, \ldots, F_{n}\right)$ which satisfies $\sum_{i=1}^{n}(1-$ $\left.F_{i}\left(l_{i}\right)\right) \leq 1$ or $\sum_{i=1}^{n} F_{i}\left(\mu_{i}-\right) \leq 1$, and if $X \leq_{\text {wco-I }} Y$ or $X \leq_{\text {wco-II }} Y$ for all $Y=\left(Y_{1}, \ldots, Y_{n}\right) \in \mathfrak{R}\left(F_{1}, \ldots, F_{n}\right)$, then $X$ is mutually exclusive.

More details about comonotonicity and mutual exclusivity can be found in Dhaene and Denuit [10], Cheung and Lo $[15,16]$, Mesfioui and Denuit [17], and Puccetti and Wang [18].

Corollary 14. Let random vectors $X=\left(X_{1}, \ldots, X_{n}\right)$ and $Y=$ $\left(Y_{1}, \ldots, Y_{n}\right)$ be elements of $\Re\left(F_{1}, \ldots, F_{n}\right)$, random variable $Z$ is independent of $\sum_{i=1}^{n} X_{i}$ and $\sum_{i=1}^{n} Y_{i}$, and if $X \leq_{w c o-I} Y$ or $X \leq_{\text {wco-II }} Y$ holds, then

$$
\sum_{i=1}^{n} X_{i}+Z \leq_{s l} \sum_{i=1}^{n} Y_{i}+Z
$$

Proof. The proof can be obtained immediately by Lemma 9 and Theorems 7 and 10.

\section{Conflicts of Interest}

The authors declare that there are no conflicts of interest regarding the publication of this article.

\section{Acknowledgments}

The research was supported by the National Natural Science Foundation of China (nos. 11571198 and 11501319), Project Funded by China Postdoctoral Science Foundation (no. 2015M582064), and the Natural Science Foundation of Shandong (nos. ZR2015AL013 and ZR2014AM021).

\section{References}

[1] H. Joe, "Multivariate concordance," Journal of Multivariate Analysis, vol. 35, no. 1, pp. 12-30, 1990.

[2] J. Dhaene and M. J. Goovaerts, "Dependency of Risks and StopLoss Orderl,” ASTIN Bulletin, vol. 26, no. 2, pp. 201-212, 1996.

[3] T.-Y. Lu and Y. Zhang, "Generalized correlation order and stoploss order," Insurance: Mathematics \& Economics, vol. 35, no. 1, pp. 69-76, 2004.

[4] M. Denuit, J. Dhaene, M. Goovaerts, and R. Kaas, Actuarial Theory for Dependent Risks: Measures, Orders and Models, John Wiley \& Sons, Hoboken, NJ, USA, 2006.
[5] J. Dhaene, S. Vanduffel, M. J. Goovaerts, R. Kaas, Q. Tang, and D. Vyncke, "Risk measures and comonotonicity: a review," Stochastic Models, vol. 22, no. 4, pp. 573-606, 2006.

[6] Z. Landsman and A. Tsanakas, "Stochastic ordering of bivariate elliptical distributions," Statistics \& Probability Letters, vol. 76, no. 5, pp. 488-494, 2006.

[7] M. Shaked and J. G. Shanthikumar, Stochastic Orders, Springer Series in Statistics, Springer, New York, NY, USA, 2007.

[8] L. Rüschendorf, "Comparison of multivariate risks and positive dependence," Journal of Applied Probability, vol. 41, no. 2, pp. 391-406, 2004.

[9] A. Müller, "Stop-loss order for portfolios of dependent risks," Insurance: Mathematics \& Economics, vol. 21, no. 3, pp. 219-223, 1997.

[10] J. Dhaene and M. Denuit, "The safest dependence structure among risks," Insurance: Mathematics \& Economics, vol. 25, no. 1, pp. 11-21, 1999.

[11] M. Shaked and J. G. Shanthikumar, Stochastic Orders and Their Applications, Academic Press, San Diego, Calif, USA, 1994.

[12] M. Denuit and M. Mesfioui, "A sufficient condition of crossing type for the bivariate orthant convex order," Statistics \& Probability Letters, vol. 83, no. 1, pp. 157-162, 2013.

[13] B. Kzldemir and N. Privault, "Supermodular ordering of Poisson arrays," Statistics \& Probability Letters, vol. 98, pp. 136-143, 2015.

[14] Y. Zhang and C. Weng, "On the correlation order," Statistics \& Probability Letters, vol. 76, no. 13, pp. 1410-1416, 2006.

[15] K. C. Cheung and A. Lo, "Characterizations of countermonotonicity and upper comonotonicity by (tail) convex order," Insurance: Mathematics \& Economics, vol. 53, no. 2, pp. 334-342, 2013.

[16] K. C. Cheung and A. Lo, "Characterizing mutual exclusivity as the strongest negative multivariate dependence structure," Insurance: Mathematics \& Economics, vol. 55, pp. 180-190, 2014.

[17] M. Mesfioui and M. M. Denuit, "Comonotonicity, orthant convex order and sums of random variables," Statistics \& Probability Letters, vol. 96, pp. 356-364, 2015.

[18] G. Puccetti and R. Wang, "Extremal dependence concepts," Statistical Science, vol. 30, no. 4, pp. 485-517, 2015. 


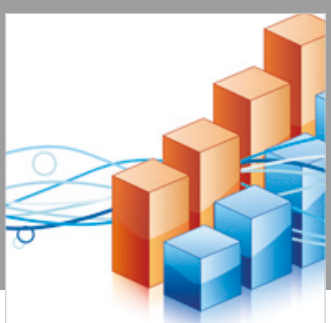

Advances in

Operations Research

\section{-n-m}
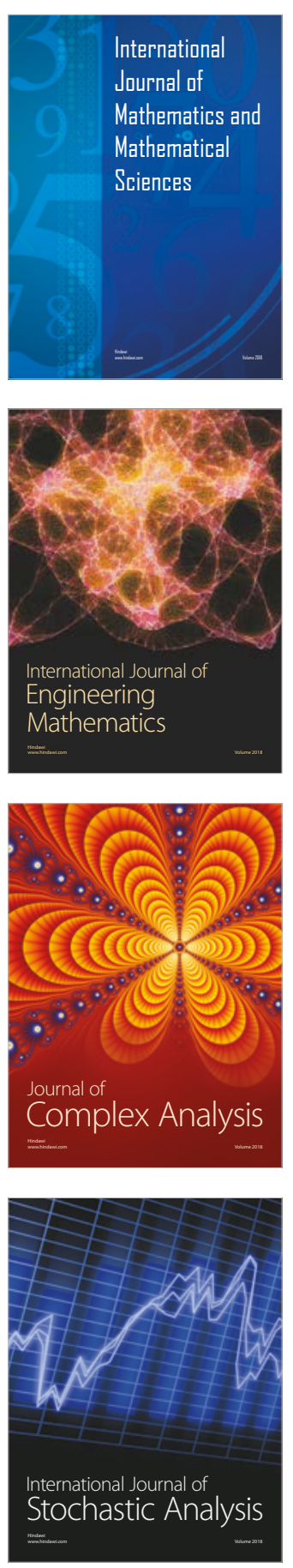
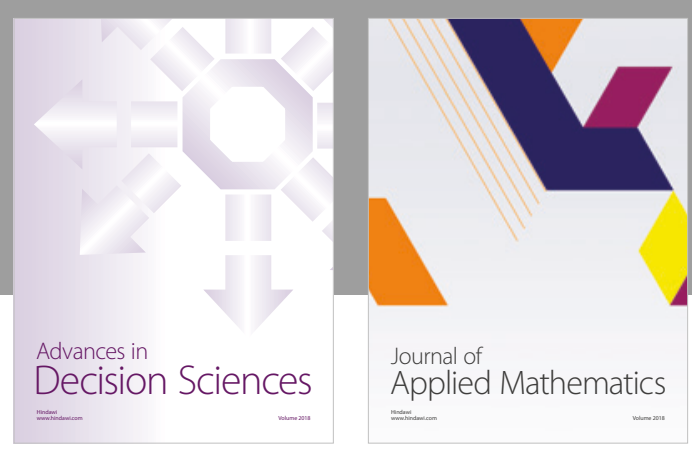

Journal of

Applied Mathematics
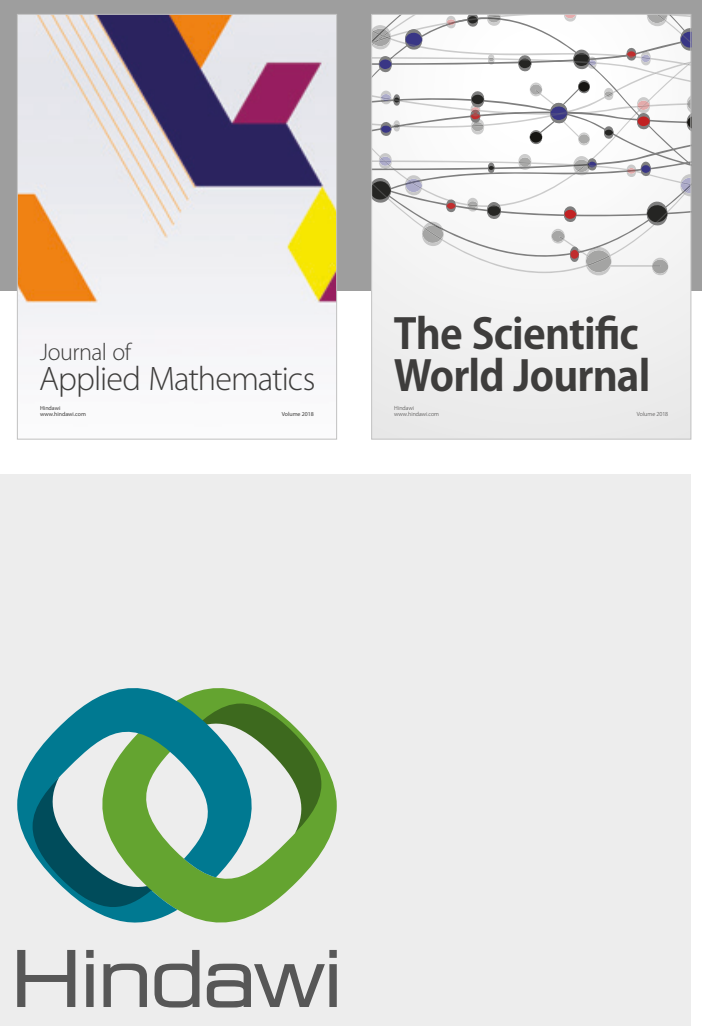

Submit your manuscripts at

www.hindawi.com

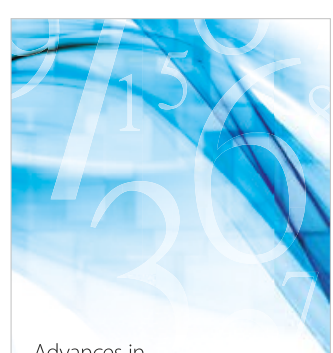

Advances in
Numerical Analysis
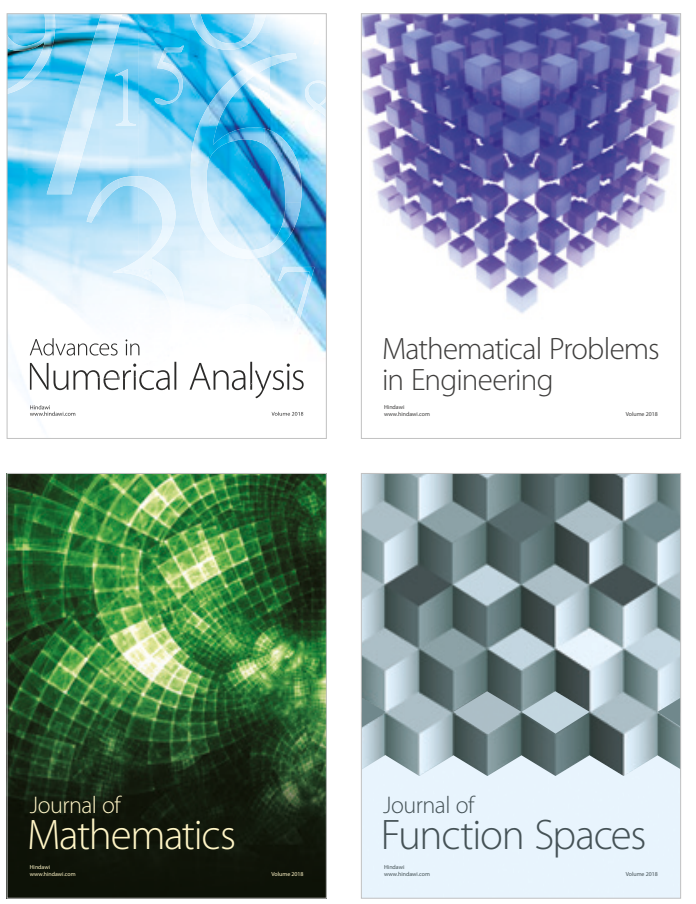

Mathematical Problems in Engineering

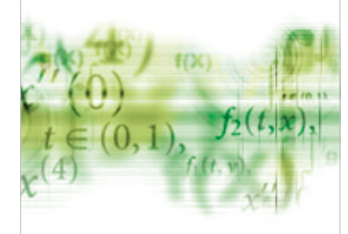

International Journal of

Differential Equations

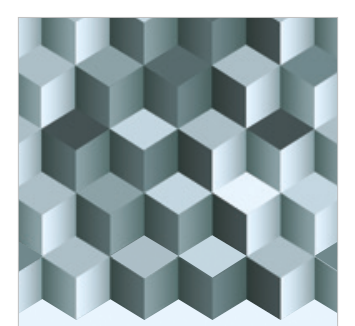

Journal of

Function Spaces

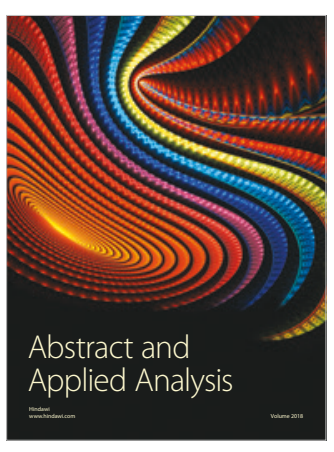

The Scientific

World Journal

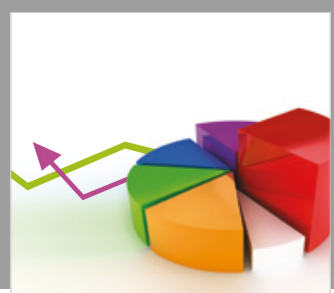

Journal of

Probability and Statistics
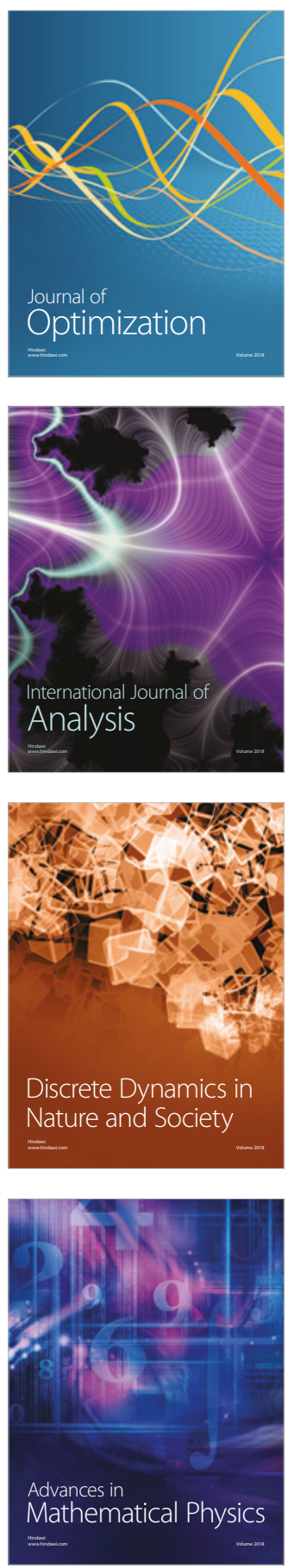